\title{
INVESTIGATION ON THE CONSTRAINT EFFECT ON THE FRACTURE TOUGHNESS ASSESSMENT OF STAINLESS STEEL AISI 304L THIN SHEETS
}

\author{
Rachid Bensaada, Madjid Almansba \\ Tizi-Ouzou University, Mechanical Engineering Department, Tizi-Ouzou, Algeria \\ e-mail: rachidbensaada@yahoo.com \\ Rabah Ferhoum, Zehra Sidhoum \\ Tizi-Ouzou University, LEC2M Laboratory, Tizi-Ouzou, Algeria \\ MALEK HABAK \\ University of Picardie Jules Verne, Laboratory of Innovative Technology, Amiens, France
}

\begin{abstract}
The aim of the study is to assess the constraint effect induced by variation of geometric parameters on fracture toughness of stainless steel 304L thin sheets. A combined experimental-computational method is used. Compact Tension (CT) tests are firstly done using a special device realized to avoid buckling problems. Finite element analysis is used including the GTN (Gurson-Tvergaard-Needleman) model based on micromechanical assumptions of ductile fracture to obtain crack propagation. The fracture toughness is evaluated using an incremental formulation of the J-Integral. The results obtained show a quantified dependency of the critical fracture toughness on the constraint effect.
\end{abstract}

Keywords: ductile damage, fracture toughness, porosity, crack propagation, J-Integral

\section{Introduction}

Much progress is done concerning the damage and fracture of metallic materials since the pioneering works of Griffith (1921) on the strain energy density of brittle materials. Concerning ductile materials, from point of view of the global fracture mechanics approach, the fracture toughness is represented by the J-Integral (Rice, 1968) when the plasticity can be considered as non-linear elasticity. This criterion is also limited to monotonic loading. From a microstructural point of view, it has been widely recognized that the ductile fracture process is a result of three main mechanisms, i.e. nucleation, growth and coalescence of cavities. The first micromechanical models resulted from the pioneering works of McClintock (1968) and Rice and Tracey (1969). These models are considered as uncoupled, the only fracture parameter is the critical void radius. They are also named as void growth models. These models are still used and some extensions are proposed, for instance, the voids interaction is taken into account in the framework of the Rice and Tracey model (Taktak et al., 2009). Concerning the coupled models, the most known and used is the Gurson model (Gurson, 1977) modified by Tvergaard and Needleman (Needleman and Tvergaard, 1984; Tvergaard, 1982). The Gurson model is concerned with the first coupling plasticity and damage variable that is considered as void volume fraction. The model has been subsequently modified by Tvergaard to take into account the voids interaction by means of calibration parameters. Finally, the model is modified by Needleman and Tvergaard introducing an effective porosity for better description of the coalescence stage. Other models based on the same assumptions are developed, for instance, the Rousselier model (Rousselier, 1981, 1987, 2001) that takes into account the void volume fraction evolution. In addition, the model is based on thermodynamic assumptions considering an additional scalar damage variable. However, the 
GTN model is the most frequently used for its consistent description of different steps of the ductile fracture process and for the physical representativity of its parameters.

Considerable efforts were made within the scientific community for determination of an intrinsic criterion for fracture toughness assessment of ductile materials (Bensaada et al., 2018; Wang et al., 2013). It has been recognized that the fracture mechanical parameters are dependent on the geometric parameters of tested specimens (Brocks et al., 2010). Among the principal issues of the classical fracture mechanics, i.e. stress intensity factor, J-Integral, we find transferability problems from a specimen to another. The problem gets more complicated for transferability from a specimen to the structure as a result of stress level dependency of these criteria (Marie, 2001). The aim of this contribution is to study the geometric effect on the fracture toughness response of AISI 304L thin sheets. This material is widely used in key industry sectors and presents interesting properties including its ability to keep its strength under large deformations (Sidhoum et al., 2018). Mechanical components are often exposed to the failure risk, hence it is important to acquire knowledge concerning the fracture toughness and its evolution. A combination of experimental tests and finite element simulations is done. The J-R curve is determined for each case. A correlation is done between the fracture toughness characterized by the critical J-Integral and the geometric parameters represented by the crack length/ligament length ratio.

\section{Experimental procedure}

Stainless steel thin sheets made of AISI 304L of three different thicknesses are used. Tensile specimens are machined according to the European standard EN-10002-1 (1991). The specimens dimensions are given in Fig. 1.

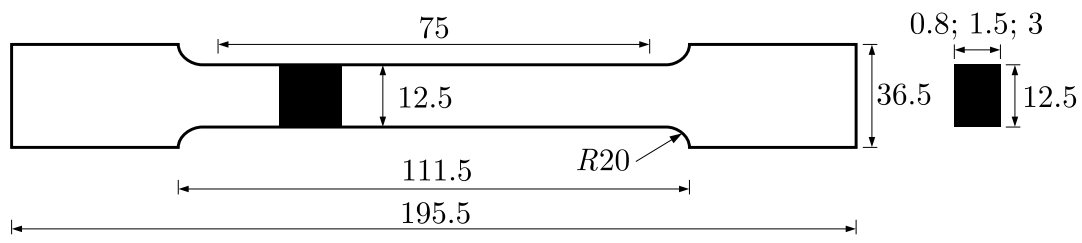

Fig. 1. Tensile test dimensions

Tests are conducted under quasi-static conditions using an Instron test machine, a $2 \mathrm{~mm} / \mathrm{min}$ displacement speed is adopted under ambient laboratory temperature. The mean results obtained in terms of the true stress-true strain curve are given in Fig. 2. The elastic and hardening properties are then determined by

$$
\varepsilon=\varepsilon_{e}+\varepsilon_{p} \quad \sigma=\left\{\begin{array}{lll}
E \varepsilon_{e} & \text { for } & \sigma \leqslant \sigma_{y} \\
\sigma_{y}+k \varepsilon_{p}^{n} & \text { for } & \sigma>\sigma_{y}
\end{array}\right.
$$

Table 1. Mechanical properties of the material studied

\begin{tabular}{|c|c|c|c|c|c|c|}
\hline$E[\mathrm{MPa}]$ & $R_{p 0.2}[\mathrm{MPa}]$ & $R_{m}[\mathrm{MPa}]$ & $A[\%]$ & $k[\mathrm{MPa}]$ & $n$ & $\nu$ \\
\hline \hline 178178 & 374 & 693 & 60 & 520 & 0.7 & 0.3 \\
\hline
\end{tabular}

The CT (Compact Tension) specimens are machined according to the ASTM E-1820 standard (ASTM, 2014). Three thicknesses are used $(0.8,1.5$ and $3 \mathrm{~mm})$ with three ligament lengths of $0.8 \mathrm{~mm}$ and $3 \mathrm{~mm}$ and four ligament lengths of $1.5 \mathrm{~mm}$ to obtain various ratios $a / W$, where $a$ is initial crack length and $W$ is specimen width. The dimensions of the specimens machined are given in Fig. 3. 


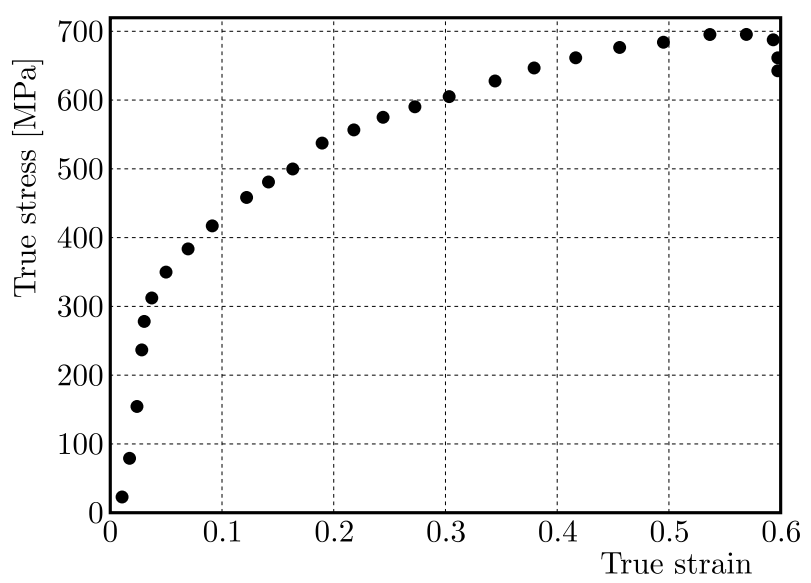

Fig. 2. True stress-true strain curve

(a)

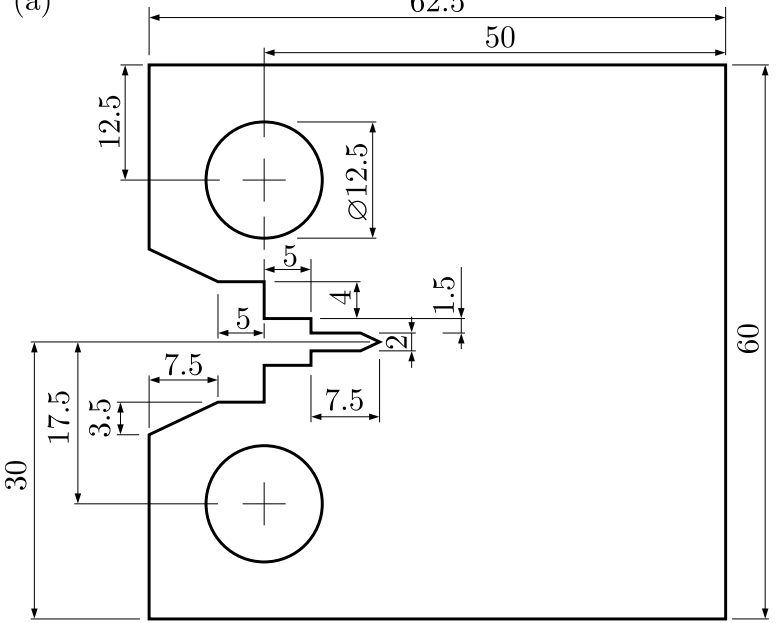

(c)

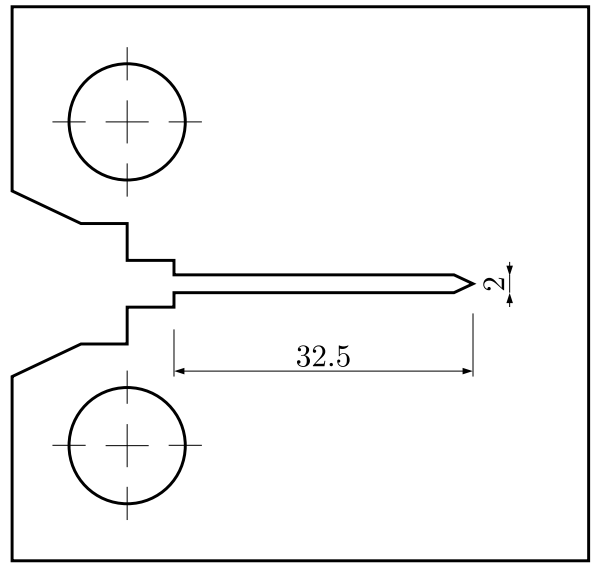

(b)

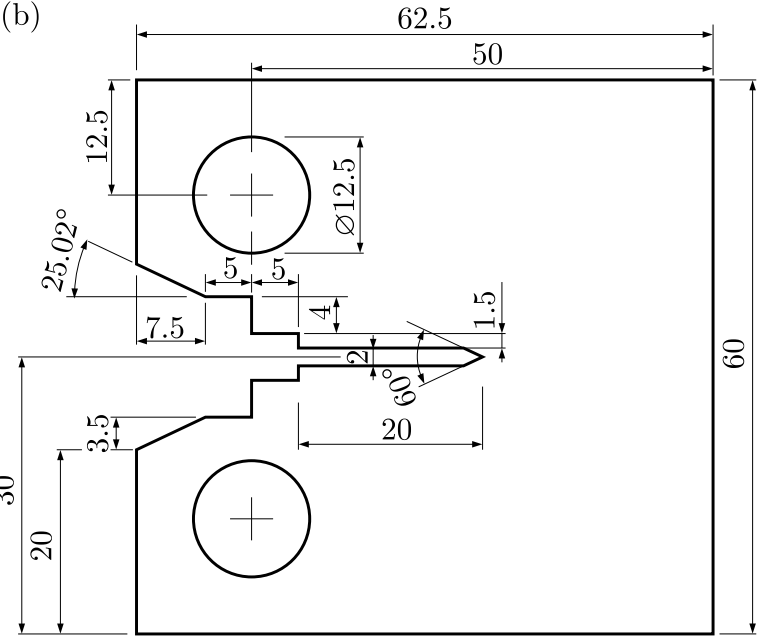

(d)

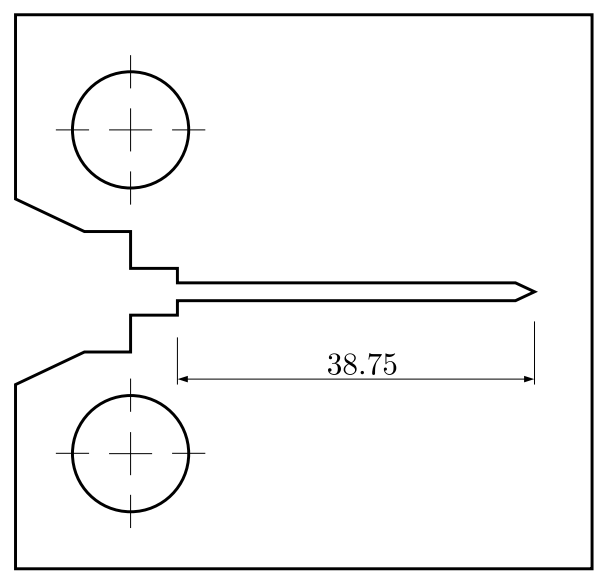

Fig. 3. CT specimens tested: (a) $a / W=0.2$, (b) $a / W=0.4$, (c) $a / w=0.6$ and (d) $a / W=0.75$

In order to avoid buckling problems, a special device inspired by the work of Shahani et al. (2010) has been incorporated, and details are given in Fig. 4. The tests were done in the same conditions as those of the mechanical characterization. The results obtained in terms of load-load line displacement curves are shown in Fig. 5. 

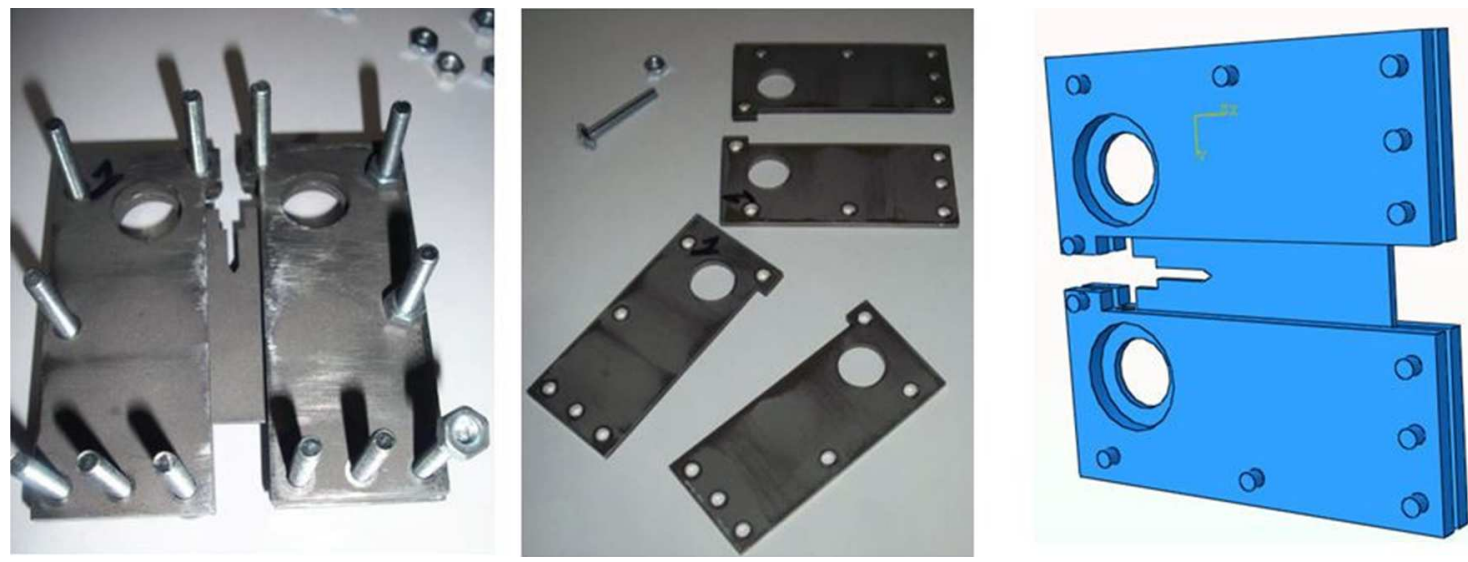

Fig. 4. Anti-buckling device for CT specimens tests
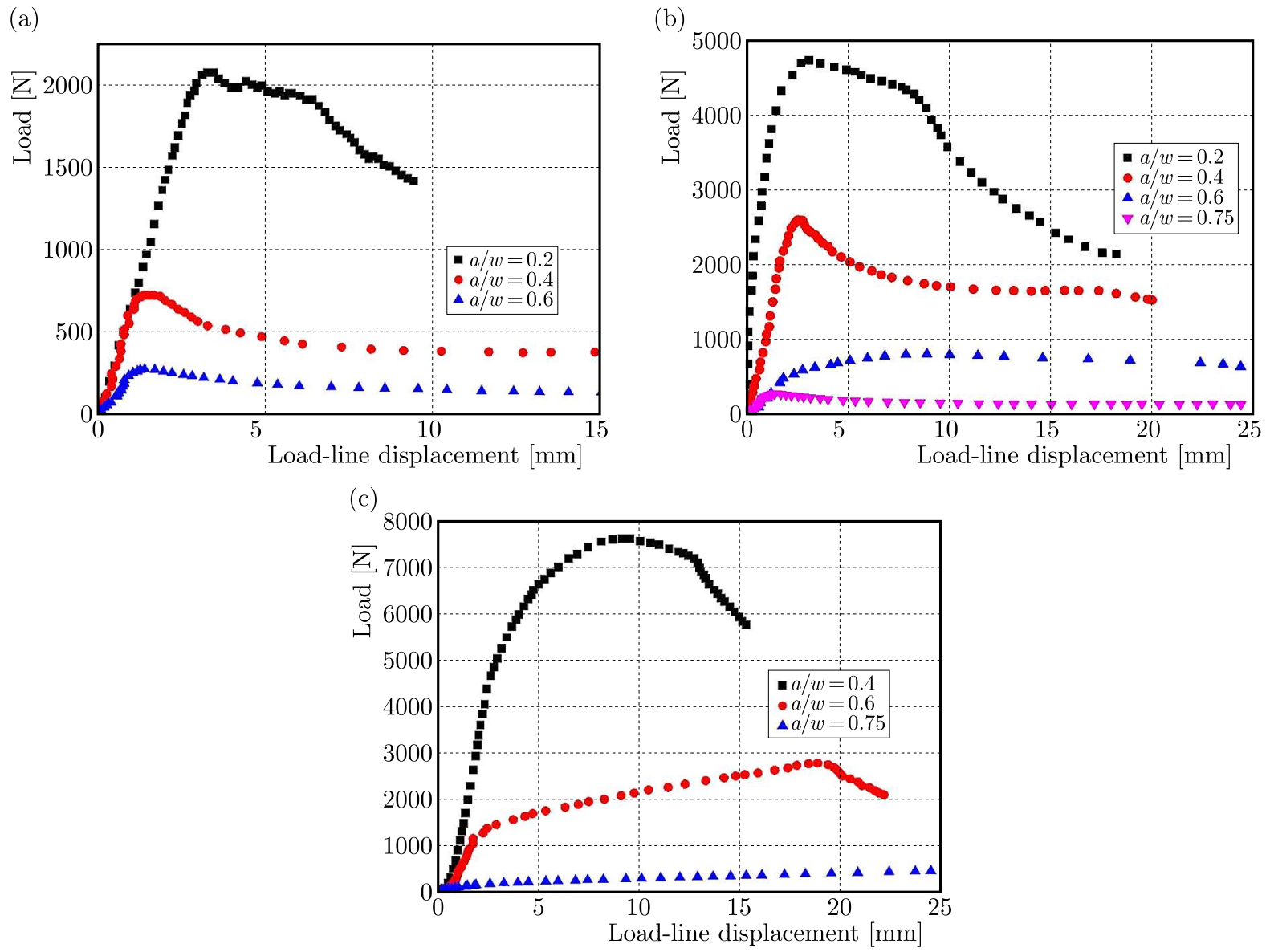

Fig. 5. Load-load line displacement curves obtained from CT tests: (a) $B=0.8 \mathrm{~mm}$, (b) $B=1.5 \mathrm{~mm}$, (c) $B=3 \mathrm{~mm}$

\section{Finite element analysis}

In order to determine the fracture toughness through the J-R curves, numerical simulations based on finite element analysis are performed. The behavior of the material is governed by the GTN model, its yield function is given as 


$$
\begin{aligned}
& \Phi_{G T N}=\frac{\Sigma_{e q}^{2}}{\bar{\sigma}^{2}}+q_{1} 2 f^{*} \cosh \left(q_{2} \frac{3}{2} \frac{\Sigma_{m}}{\bar{\sigma}}\right)-\left(1+q_{3} f^{* 2}\right)=0 \\
& f^{*}= \begin{cases}f & \text { if } \quad f \leqslant f_{c} \\
f_{c}+\frac{f_{u}^{*}-f_{c}}{f_{F}-f_{c}}\left(f-f_{c}\right) & \text { if } \quad f>f_{c}\end{cases} \\
& \dot{f}=\dot{f}_{\text {growth }}+\dot{f}_{\text {nucleation }} \quad \dot{f}_{\text {growth }}=(1-f) \dot{\varepsilon}_{k k}^{p}
\end{aligned}
$$

where $\Sigma_{e q}$ and $\Sigma_{m}$ are, respectively, the von-Mises equivalent stress and the hydrostatic stress. $\bar{\sigma}$ is the actual stress due to hardening, $q_{1}, q_{2}$ and $q_{3}$ are Tvergaard's calibration parameters (Tvergaard, 1982). $f^{*}$ is the effective void volume fraction introduced by Needleman and Tvergaard (1984). The GTN model requires identification of its parameters. For sake of simplification, some parameters are fixed in the beginning, e.g. the Tvergaard $q_{i}$ parameters that are taken as $q_{1}=1.5, q_{2}=1, q_{3}=q_{1}^{2}$. The parameter $A$, Eq. $(3.2)_{2}$, follows a normal distribution. The nucleation parameters are also fixed in accordance to the previous studies as $\varepsilon_{N}=0.3$ and $S_{N}=0.1$ (Wilsius, 1999; Kiran and Khandelwal, 2014), where $\varepsilon_{N}$ is the strain to nucleation and $S_{N}$ is the standard derivation.

$$
\dot{f}_{\text {nucleation }}=A \dot{\overline{\varepsilon^{p}}} \quad A=\frac{f_{N} \exp \left[-\frac{1}{2}\left(\frac{\varepsilon_{e}^{p}-\varepsilon_{N}}{S_{N}}\right)\right]}{S_{N} \sqrt{2 \pi}}
$$

The void volume fraction parameters are calibrated using the tensile test. Simulations are done using the finite element software ABAQUS. Quasi-static conditions are respected and the geometric non-linearity is taken into account. Many simulations are performed until the experimental calibration is achieved. The finite element mesh of the traction specimen is given in Fig. 6. A three-dimensional finite element analysis is performed. The part is meshed with C3D8R elements (3D 8-node linear brick with reduced integration elements).

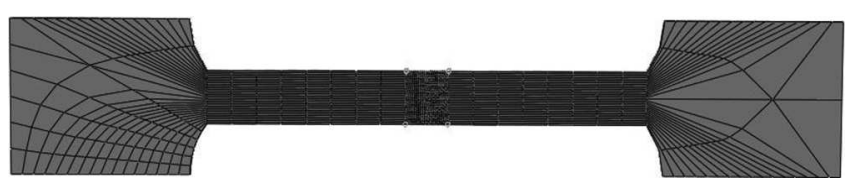

Fig. 6. Finite element mesh of the tensile specimen

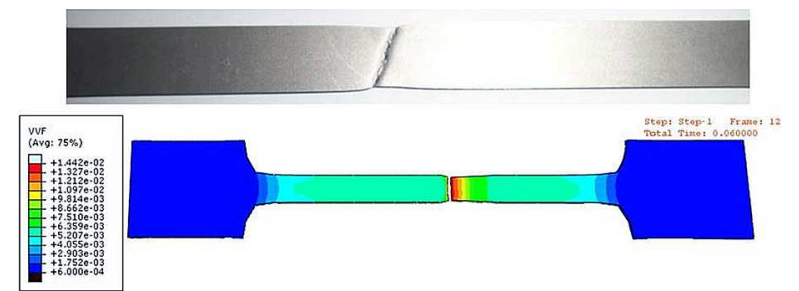

Fig. 7. Tensile specimen fracture

A comparison between the fracture of the specimen obtained by numerical simulation and experimental test is shown in Fig. 7. The selected parameters of the GTN model are given in Table 2. Many simulations have been done to choose those parameters. The known dependency between the void volume fraction parameters is taken into account $f_{0}$, considered as a material parameter, is fixed according to the stress-strain response given by the tensile test. The couple $\left(f_{N}, f_{C}\right)$ is the most difficult to fix given the complexity of the nucleation and coalescence phenomenas. One parameter is fixed, the other is varied in order to choose its corresponding value and vice versa. The chosen parameters are in accordance with the tensile response of the 
material. The value of $f_{F}$ is chosen according to the material strain to fracture. The calibration of the tensile test in terms of the stress-strain curve is given in Fig. 8. We note a small difference between the experimental data and the prediction given by the GTN model due to the softening taken into account at the beginning of the hardening given that the plastic potential is coupled to the damage variable, i.e. porosity. This difference is due to some complex effect of the material behavior that is not described by the GTN model, i.e. the TRIP effect. The heterogeneous character of the material and its heating are not taken into account by the model, therefore, the shear band observed experimentally is not reproduced, but the fracture is satisfactory predicted.

Table 2. Selected parameters of the GTN model

\begin{tabular}{|c|c|c|c|c|c|}
\hline$f_{0}$ & $f_{N}$ & $f_{C}$ & $f_{F}$ & $\varepsilon_{N}$ & $S_{N}$ \\
\hline \hline 0.0006 & 0.004 & 0.012 & 0.02 & 0.3 & 0.1 \\
\hline
\end{tabular}

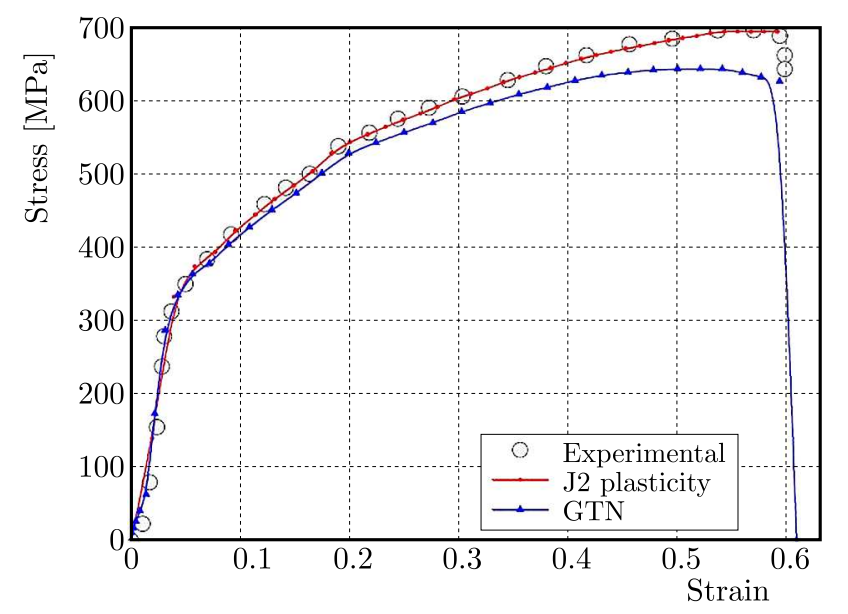

Fig. 8. Stress-strain curve calibration of the GTN model

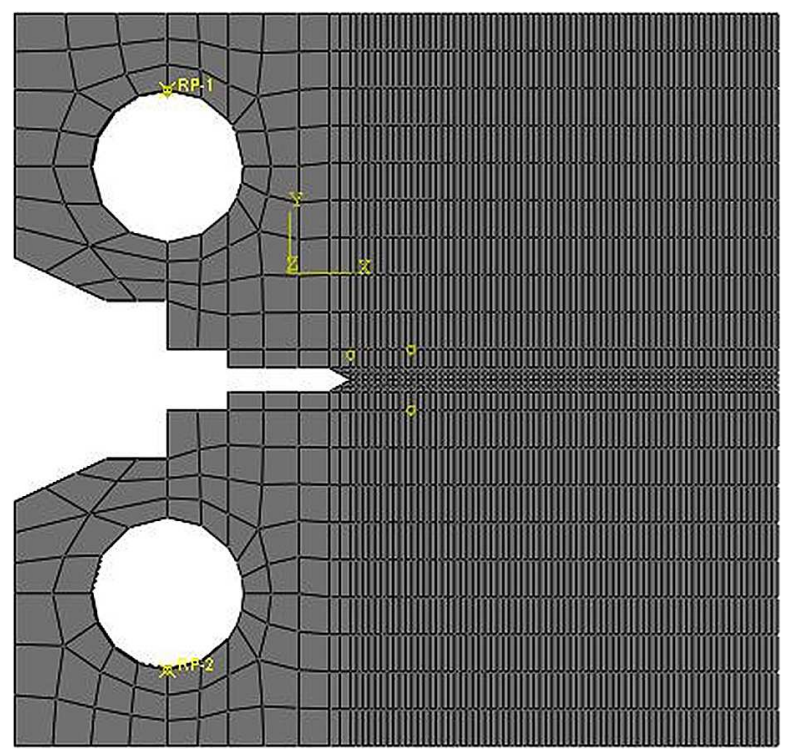

Fig. 9. Finite element mesh of CT specimens

Simulations of CT tests are subsequently performed using the GTN model with the selected parameters. A 3D finite element analysis is done. The typical mesh of CT specimens is given in Fig. 9. The same C3D8R elements used for the tensile test are selected for these simulations. 
The results obtained in terms of crack propagation (Fig. 10) are used in order to determine the fracture toughness for each case.
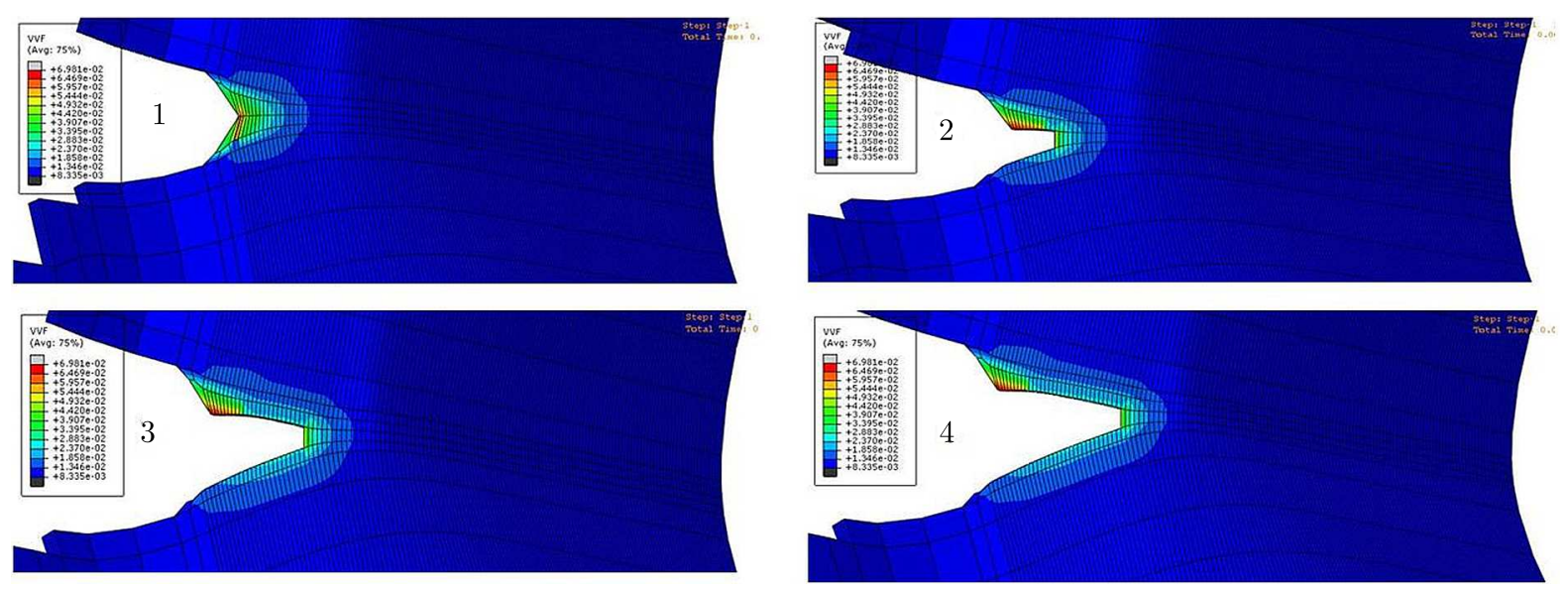

Fig. 10. Simulation of crack propagation of CT specimens

\section{Fracture toughness assessment}

Once the experimental and numerical results are available, a combination of load-displacement results of CT specimens and crack propagation data obtained from finite element analysis is used to determine the J-R curve according to the ASTM E-1820 standard (ASTM, 2014) using the following set of equations.

The J-Integral formulation used in the present investigation is decomposed residually to an elastic and plastic part as follows

$$
J=J_{e l}+J_{p l}
$$

Inserting the elastic part explicity, Eq. (4.1) is written as follows

$$
J=\frac{K^{2}\left(1-\nu^{2}\right)}{E}+J_{p l}
$$

The plastic part is given by the following equation

$$
J_{p l}=\frac{\left(2+0.522 \frac{b_{0}}{W}\right) A_{p l}}{B_{N} b_{0}}
$$

where $K$ is the stress intensity factor, $A_{p l}$ is the area under the load-load line displacement curve, $B_{N}$ is the net thickness of the specimen, $B$ is the specimen thickness. $b_{0}=W-a_{0}$ is the ligament length, where $W$ is the specimen width and $a_{0}$ is the initial crack length. $V$ is the total load-line displacement and $V_{p l}$ is the plastic part of the load-line displacement.

The J-Integral is written from an incremental point of view. An iterative formulation is used. At the $i$-th step, for a given $a(i), V(i)$ and $P(i)$, where $P$ is the load capacity, the calculations are done as follows

$$
J_{(i)}=\frac{K_{(i)}^{2}\left(1-\nu^{2}\right)}{E}+J_{p l} \quad K_{(i)}=\frac{P_{(i)}}{\sqrt{B B_{N} W}} f\left(\frac{a_{0}}{W}\right)
$$




$$
\begin{aligned}
f\left(\frac{a_{0}}{W}\right) & =\frac{\left(2+\frac{a_{0}}{W}\right)\left[0.886+4.64 \frac{a_{0}}{W}-13.32\left(\frac{a_{0}}{W}\right)^{2}+14.72\left(\frac{a_{0}}{W}\right)^{3}-5.6\left(\frac{a_{0}}{W}\right)^{4}\right]}{\sqrt{\left(1-\frac{a_{0}}{W}\right)^{3}}} \\
J_{p l(i)} & =\left(J_{p l(i-1)}+\frac{2+0.522 \frac{b_{(i-1)}}{W}}{b_{(i-1)}} \frac{A_{p l(i)}-A_{p l(i-1)}}{B_{N}}\right)\left(1-\frac{a_{(i)}-a_{(i-1)}}{b_{(i-1)}}\right)
\end{aligned}
$$

The difference $A_{p l(i)}-A_{p l(i-1)}$ represents the increment of the plastic part of the area under the load-load line displacement curve. $J_{p l(i)}$ is the plastic J-Integral for an advanced crack to the point $i$. This quantity is obtained in two steps by introducing $J_{p l(i-1)}$ and adding the total cumulative result for the crack growth increment at the $i$-th step. The quantity $A_{p l(i)}$ can be calculated using the following equation

$$
A_{p l(i)}=A_{p l(i-1)}+\frac{\left(P_{(i)}+P_{(i-1)}\right)\left(V_{p l(i)}-V_{p l(i-1)}\right)}{2}
$$

In the present contribution, a combination of experimental results and numerical simulations is used to obtain the J-R curves. Many methods are used for the determination of this criterion, among them we can find the unloading compliance method. It consists in performing the elastic consecutive unloading. This method is efficient for the determination of crack propagation in addition to fracture energy but the unloading is not in accordance with the principle of the J-integral, i.e. only suitable for a monotonic radial loading. The set of equations presented above is implemented into a MATLAB routine in an iterative form. The input variables are the load-load line displacement data and the associate incremental crack propagation extracted from ABAQUS. The output variable is the J-R curve using Eqs. (4.1)-(4.5). The results obtained in terms of J-R curves for all the CT tests are given in Fig. 11.

(a)

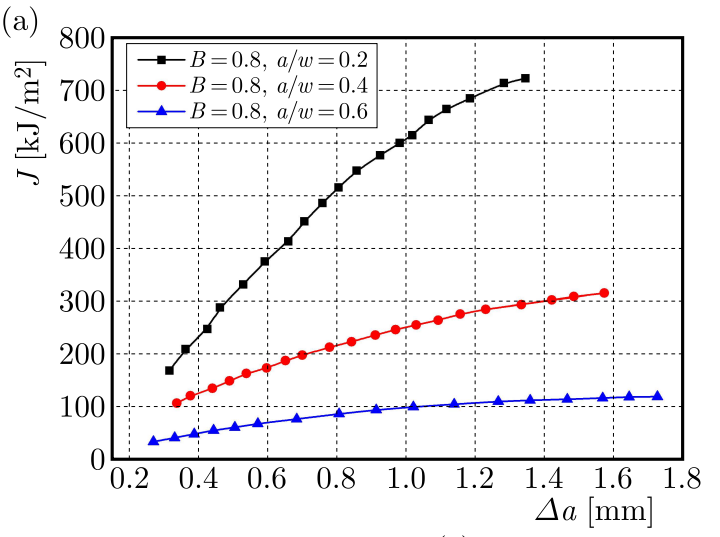

(b)

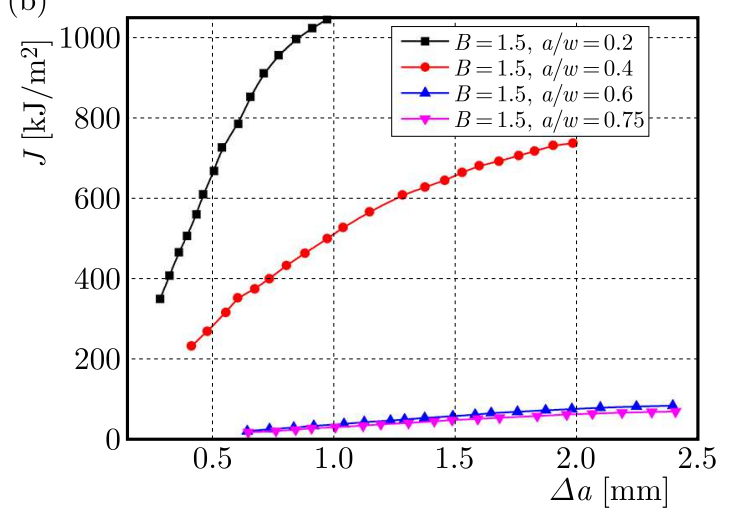

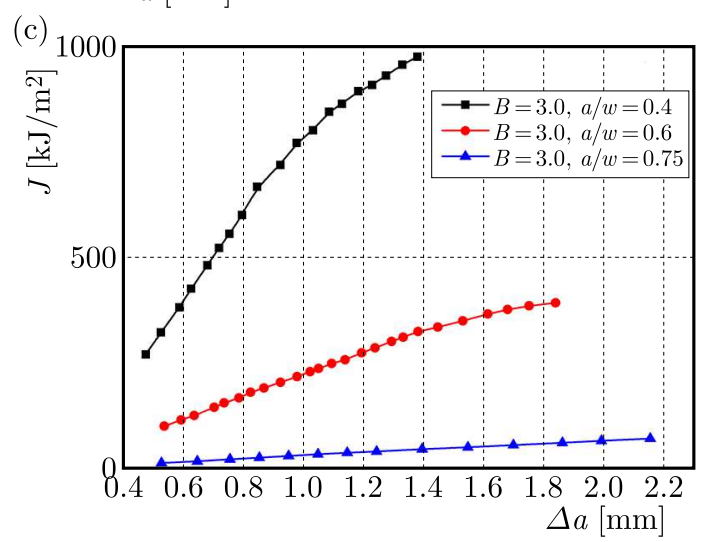

Fig. 11. J-R curves with various specimen thicknesses and ligament lengths 
The critical value of the J-Integral is extracted from the J-R curves shown in Fig. 11. The details of the values obtained for this criterion are given in Table 3. The evolution is presented in Fig. 12.

Table 3. Evolution of $J_{I C}\left[\mathrm{KJ} / \mathrm{m}^{2}\right]$ with the evolution of geometric parameters

\begin{tabular}{|c|c|c|c|c|}
\hline \multirow{2}{*}{$B$} & \multicolumn{4}{|c|}{$a / W$} \\
\cline { 2 - 5 } & 0.2 & 0.4 & 0.6 & 0.75 \\
\hline \hline 0.8 & 291 & 192 & 65 & - \\
\hline 1.5 & 673 & 459 & 31 & 26 \\
\hline 3 & - & 462 & 133 & 15 \\
\hline
\end{tabular}

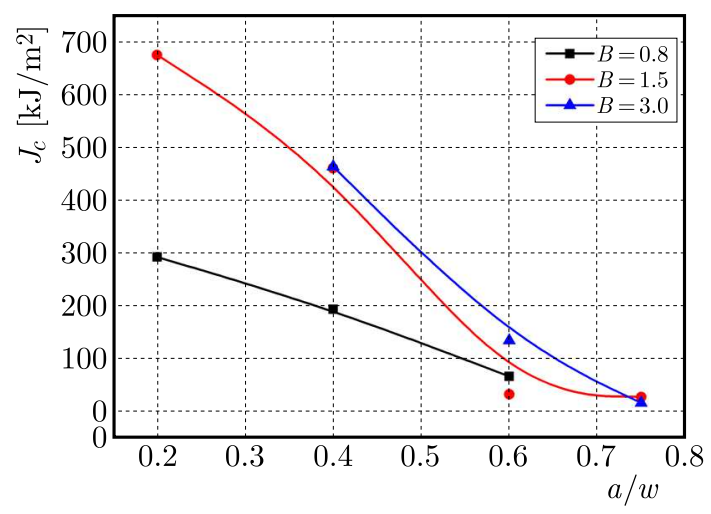

Fig. 12. Fracture toughness versus ligament length

From the results obtained, we can conclude that the global parameter $J$ depends on the geometric parameters, which can be surpassed by constraint dependence, but the latter can be quantified. For a weak ratio $a / W$, the fracture toughness is high and proportional to the specimen thickness. From $a / W=0.5$, the fracture toughness variation is negligible with thickness variation. We can also conclude from this investigation that for $a / W=0.6$, the $J_{C}$ variation is weak. In previous works (Neimitz, 2006), it was noted that the fracture toughness could decrease with the increasing thickness for a high $a / W$ ratio.

The fracture toughness obtained for $a / W=0.75$ and thickness of $B=1.5 \mathrm{~mm}$ is higher than the one obtained for a $3 \mathrm{~mm}$ thickness specimen for the same $a / W$ ratio. The results obtained in the present work are in accordance with those obtained in previous studies (Neimitz, 2006; Shahani et al., 2010). We can conclude that $J_{C}$ cannot be considered as an intrinsic criterion for fracture characterization, but it can be used to quantify the fracture toughness given that a general tendency is obtained.

\section{Conclusions}

The aim of this investigation is to study the constraint effect on fracture toughness of stainless steel AISI 304L thin sheets. A combination of experimental tests and finite element simulations is used. Firstly, mechanical characterization is performed in order to determine elastic and hardening properties of the material and also for determination of suitable parameters of the GTN model used in the present work. Specimens for Compact Tension (CT) tests were subsequently machined and an anti-buckling device was designed. Tests were performed on CT specimens in quasi-static conditions, and associate finite element simulations were also done. The results obtained in terms of load-load line displacement experimental data and crack propagation from 
numerical simulation are used to assess the fracture toughness using the ASTM E-1820 Standard. The J-integral formulation is written incrementally using the MATLAB software. The critical value of the J-Integral $\left(J_{C}\right)$ is determined from the J-R curves obtained from the precedent step. The results show that $J_{C}$ depends on the geometric parameters for the obvious reason that the parameter is proportional to the material load capacity. An other conclusion is that this dependence can be quantified given that a general tendency is obtained. The $J_{C}$ value can be normalized by the geometric parameters to obtain an intrinsic fracture toughness parameter and to avoid multiple specimens tests. This method can be useful for optimization in terms of the number of specimens required to fracture characterization of metallic materials.

For future work, it would be interesting to experiment the transferability of fracture toughness parameters from specimens to mechanical components by the assessment of the stress state, given the constraint dependence of these parameters.

\section{References}

1. ASTM, 2014, E1820-13: Standard Test Method for Measurement of Fracture Toughness

2. Bensaada R., Almansba M., Ferhoum R., Sidhoum Z., 2018, Ductile fracture study of stainless steel AISI 304L thin sheets using the EWF method and cohesive zone modeling, Journal of Failure Analysis and Prevention, 18, 5, 1181-1190

3. Brocks W., Anuschewski P., Scheider I., 2010, Ductile tearing resistance of metal sheets, Engineering Failure Analysis, 17, 3, 607-616

4. EN-10002-1, 1991, Metallic materials - Tensile testing, European Commitee for Standardization

5. Griffith A.A., 1921, The phenomena of rupture and flow in solids, Philosophical Transactions of the Royal Society of London, Series A, 221, 163-198

6. Gurson A.L., 1977, Continuum theory of ductile rupture by void nucleation and growth. Part I Yield criteria and low rules for porous ductile media, ASME, Journal of Material Engineering and Technology, 99, 2-15

7. Kiran R., Khandelwal K., 2014, Gurson model parameters for ductile fracture simulation in ASTM A992 steels, Fatigue and Fracture of Engineering Materials and Structures, 37, 2, 171-183

8. MArie S., 2001, Approche energetique de la rupture ductile, Ph.D Thesis, CEA Saclay

9. McClintock F.A., 1968, Local criteria for ductile fracture, International Journal of Fracture Mechanics, 4, 101-130

10. Needleman A., Tvergand V., 1984, An analysis of ductile rupture in notched bars, Journal of Mechanics and Physics of Solids, 32, 461-490

11. Neimitz A., 2006, Fracture toughness of structural elements: the influence of the in- and out-of-plane constraints of fracture toughness, Materials Science, 2, 1, 61-77

12. RiCe J.R., 1968, A path independent integral and the approximate analysis of strain concentration by notches and cracks, Journal of Applied Mechanics, 35, 2, 379-386

13. Rice J.R., Tracey D.M., 1969, On the ductile enlargement of voids in triaxial stress fields, Journal of Mechanics and Physics of Solids, 17, 201-217

14. Rousselier G., 1981, Finite Deformation Constitutive Relations Including Ductile Fracture Damage, North-Holland Publishing, 331-355

15. Rousselien G., 1987, Ductile fracture models and their potential in local approach of fracture, Nuclear Engineering and Design, 105, 97-111

16. Rousselier G., 2001, Dissipation in porous metal plasticity and ductile fracture, Journal of the Mechanics and Physics of Solids, 49, 1727-1746 
17. Shahani A.R., Rastegar M., Dehkordi M.B., Kashani H.M., 2010, Experimental and numerical investigation of thickness effect on ductile fracture toughness of steel alloy sheets, Engineering Fracture Mechanics, 77, 646-659

18. Sidhoum Z., Ferhoum R., Almansba M., Bensaada R., Habak M., Aberkane M., 2018, Experimental and numerical study of the mechanical behavior and kinetics of the martensitic transformation in 304L TRIP steel: applied to folding, International Journal of Advanced Manufacturing Technology, 97, 5-8, 2757-2765

19. TAktak R., Benseddiq N., Imad A., 2009, Analysis of ductile tearing using a local approach to fracture, Fatigue and Fracture of Engineering Materials and Structures, 32, 6, 525-530

20. Tvergand V., 1982, On localization in ductile materials containing spherical voids, International Journal of Fracture, 19, 237-252

21. Wang J., Wang G.Z., Xuan F.Z., Tu S.T., 2013, Derivation of constraint dependent J-R curves based on modified T-stress parameter and GTN model for a low-alloy steel, International Journal of Fracture, 183, 155-168

22. Wilsius J., 1999, Etude expérimentale et numérique de la déchirure ductile basée sur des approches locales de mécanique de la rupture, Ph.D. Thesis, Université des Sciences et Technologies de Lille 